\title{
Inhibition of p70S6K2 down-regulates Hedgehog/GLI pathway in non-small cell lung cancer cell lines Shinji Mizuarai ${ }^{1}$, Aki Kawagishi ${ }^{1}$ and Hidehito Kotani*1,2
}

\author{
Address: ${ }^{1}$ Departments of Oncology, Tsukuba Research Institute, Merck Research Laboratories, Banyu Pharmaceutical Co, Ltd, Tsukuba, Ibaraki \\ 300-2611, Japan and 2Corporate services, Banyu Pharmaceutical Co, Ltd, Chiyoda-Ku, Tokyo 102-8667, Japan \\ Email: Shinji Mizuarai - shinji_mizuarai@merck.com; Aki Kawagishi - aki_kawagishi@merck.com; \\ Hidehito Kotani* - hidehito_kotani@merck.com \\ * Corresponding author
}

Published: 6 July 2009

Molecular Cancer 2009, 8:44 doi:10.1 I86/1476-4598-8-44
Received: II April 2009

Accepted: 6 July 2009

This article is available from: http://www.molecular-cancer.com/content/8///44

(c) 2009 Mizuarai et al; licensee BioMed Central Ltd.

This is an Open Access article distributed under the terms of the Creative Commons Attribution License (http://creativecommons.org/licenses/by/2.0), which permits unrestricted use, distribution, and reproduction in any medium, provided the original work is properly cited.

\begin{abstract}
Background: The Hedgehog $(\mathrm{HH})$ pathway promotes tumorigenesis in a diversity of cancers. Activation of the $\mathrm{HH}$ signaling pathway is caused by overexpression of $\mathrm{HH}$ ligands or mutations in the components of the $\mathrm{HH} / \mathrm{GLII}$ cascade, which lead to increased transactivation of GLI transcription factors. Although negative kinase regulators that antagonize the activity of GLI transcription factors have been reported, including GSK3 $\beta$, PKA and CKIs, little is known regarding positive kinase regulators that are suitable for use on cancer therapeutic targets. The present study attempted to identify kinases whose silencing inhibits $\mathrm{HH} / \mathrm{GLI}$ signalling in non-small cell lung cancer (NSCLC).
\end{abstract}

Results: To find positive kinase regulators in the $\mathrm{HH}$ pathway, kinome-wide siRNA screening was performed in a NSCLC cell line, A549, harboring the GLI regulatory reporter gene. This showed that p7056K2-silencing remarkably reduced GLI reporter gene activity. The decrease in the activity of the $\mathrm{HH}$ pathway caused by $\mathrm{p} 7056 \mathrm{~K} 2$-inhibition was accompanied by significant reduction in cell viability. We next investigated the mechanism for p70S6K2-mediated inhibition of GLII transcription by hypothesizing that GSK3 $\beta$, a negative regulator of the $\mathrm{HH}$ pathway, is activated upon p70S6K2-silencing. We found that phosphorylated-GSK3 $\beta$ (Ser9) was reduced by p7056K2silencing, causing a decreased level of GLII protein. Finally, to further confirm the involvement of p70S6K2 in GLII signaling, down-regulation in GLI-mediated transcription by PI3KCA-inhibition was confirmed, establishing the pivotal role of the PI3K/P70S6K2 pathway in GLII cascade regulation.

Conclusion: We report herein that inhibition of p70S6K2, known as a downstream effector of the PI3K pathway, remarkably decreases GLI-mediated transactivation in NSCLC by reducing phosphorylated-GSK3 $\beta$ followed by GLII degradation. These results infer that p70S6K2 is a potential therapeutic target for NSCLC with hyperactivated HH/GLI pathway.

\section{Background}

The Hedgehog (HH) signaling pathway is essential for the control of multiple cell proliferation processes such as pattern formation, stem cell maintenance and tumorigenesis $[1,2]$. Activation of $\mathrm{HH}$ signaling is initiated by the $\mathrm{HH}$ ligand binding to its receptor, Patched (PTCH), lead- 
ing to relief of PTCH mediated repression of a G proteincoupled receptor, Smoothened (SMOH) [3]. This event is followed by the accumulation of unphosphorylated GLI transcription factors at multiple amino acid residues [4]. The hypophosphorylation of GLI causes its stabilization, which facilitates the transactivation of GLI regulatory genes involved in cell cycle progression and apoptosis inhibition such as Cyclin D1 [5], $\gamma$-catenin [6], and selfinduction of GLI1 [7]. The eventual transactivation/transsuppression of a number of genes by GLI transcription factors is of significance for exertion of the HH signaling cascade's functions in normal-cell development or tumorigenesis. The regulation of $\mathrm{HH}$ signaling is controlled by the conserved negative kinase regulators, protein kinase A (PKA), casein kinases (CK1a and CK1e) and glycogen synthase kinase $3 \beta$ (GSK3 $\beta$ ) which cooperatively phosphorylate and inactivate GLI factors [8-10]. Up-regulation of $\mathrm{PTCH}$ expression by $\mathrm{HH}$ signaling is also an important feature of negative feedback [7]. Positive regulation is controlled by the feedback loop of GLI transcription factors which directly induce expression via binding to their promoters [7]. Although the mechanism for coordinated regulation of GLI mediated transcription by $\mathrm{HH}$ ligands and downstream positive and negative effectors has been progressively investigated, further analysis to decipher the components involved in the HH cascade is eagerly anticipated.

Along with the multiple cellular processes and functions known to be derived from $\mathrm{HH}$ cascade activation, recent findings showing that the $\mathrm{HH}$ pathway plays a pivotal role in stem cell maintenance have attracted great attention, especially in the field of cancer research as a new potential therapeutic target pathway for the treatment of various types of cancers $[5,11,12]$. The aberrant up-regulation of the $\mathrm{HH}$ pathway in tumorigenesis was first reported in basal cell carcinomas resulting from either loss-of-function mutation in PTCH $[13,14]$ or gain-of-function mutation in $\mathrm{SMOH} \mathrm{[15].} \mathrm{The} \mathrm{mutations} \mathrm{or} \mathrm{deregulated}$ expression in PTCH and SMOH have been subsequently reported in various studies of brain, skin and muscle cancers $[16,17]$, which are now categorized as ligand-independent $\mathrm{HH}$ cascade-activated cancers. Recently, a subset of non-small cell lung cancer (NSCLC) was found to be hyperactive in the HH/GLI pathway independent of the ligands by expressing high level of GLI1 protein [18]. The other type of cancer in which the HH pathway is up-regulated is ligand-dependent cancer, including prostate cancer [19], breast cancer [20], pancreatic carcinoma [21], and small cell lung carcinoma [22]. The evidence provided in these studies that the HH pathway is activated in a wide range of cancers suggests the importance of identification of effective therapeutic targets to interfere with the HH pathway [23]. For ligand independent cancers there is a particularly urgent need to find effective targets to sup- press the GLI cascade due to the ineffectiveness of SMOH inhibitors and other modalities to inhibit upstream components of the HH/GLI cascade [18].

p70S6K2 is a member of the ribosomal S6 kinase family and is involved in protein synthesis and cell proliferation $[24,25]$. Increased activity or overexpression of p70S6K1/ 2 has been reported in several types of cancers [26-28]. p70S6K2 is known to mainly work downstream of the phosphoinositide 3-kinase (PI3K) pathway [29,30]. Upregulation of PI3K signaling by the activating mutation in PI3K; the inactivating mutation in phosphatase and tensin homolog (PTEN); or, receptor tyrosine kinase (RTK)s activation through mitogenic stimuli, results in an increase in serine-threonine kinase AKT activity, which leads to the inactivating phosphorylation of tuberin (TSC), and the activation of mammalian target of rapamycin (mTOR) [29,31]. The increased activity of mTOR drives the subsequent activation of its effectors including p70S6K1/2 and 4E-BP1 [27]. The phosphorylated and activated forms of p70S6K2 and 4E-BP1 cooperatively promote translational up-regulation of the proteins needed for cell cycle promotion. The functional role of p70S6K1/2 in the PI3K/mTOR cascade has been well established in the vast majority of cancer and development research [29-31], and the role of p70S6K inhibition in suppressing PI3K pathway-activated cancers has been extensively studied. However, the involvement of p70S6K in the regulation of the $\mathrm{HH}$ signaling pathway has not been analyzed.

In this study, a kinome-wide siRNA screen was performed to identify kinases whose silencing inhibits HH/GLI signaling in NSCLC. We found that p70S6K2-silencing by siRNA decreases GLI regulatory transcription ability in NSCLC through modulating GSK3 $\beta$. This report provides the first evidence that p70S6K2 positively regulates the $\mathrm{HH}$ cascade and could serve as a therapeutic target in GLI1 cascade-activated NSCLC independent of HH ligands.

\section{Results \\ Kinome small interfering RNA (siRNA) screening to find Hedgehog $(H H)$ pathway regulatory kinases}

It has previously been reported that the HH/GLI1 pathway is activated in some portion of NSCLC cell lines and primary lung tumors [18]. Expression of GLI1 transcription factor, which is a surrogate index of HH/GLI1 activation level, was examined in a panel of NSCLC cells lines to find a suitable cell line for a kinome-wide small interfering RNA (siRNA) screen. Consistent with previous studies, it was found that various levels of GLI1 were expressed in the cell lines, indicating that the HH/GLI1 pathway plays a pivotal role in NSCLC cancer cell progression (Fig. 1A). Of the eight cell lines examined, four showed activated HH/GLI1 pathways (A549, H522, PC13 
A

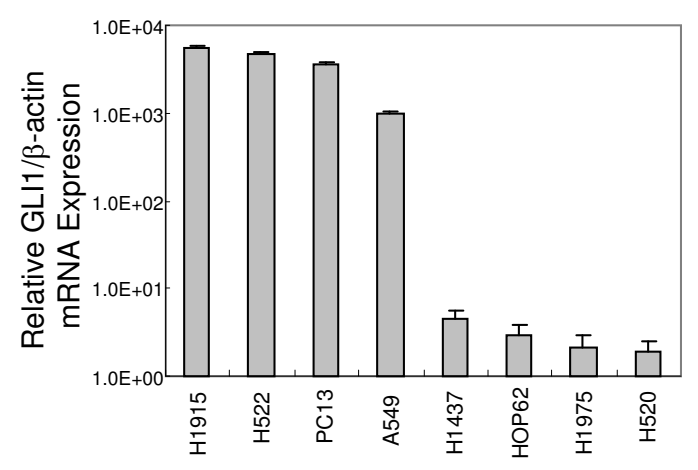

B

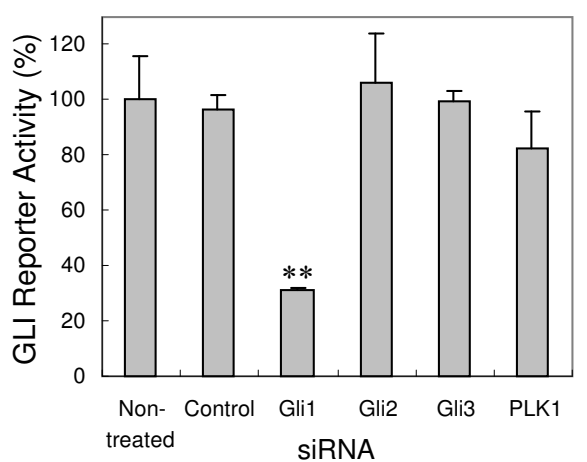

C

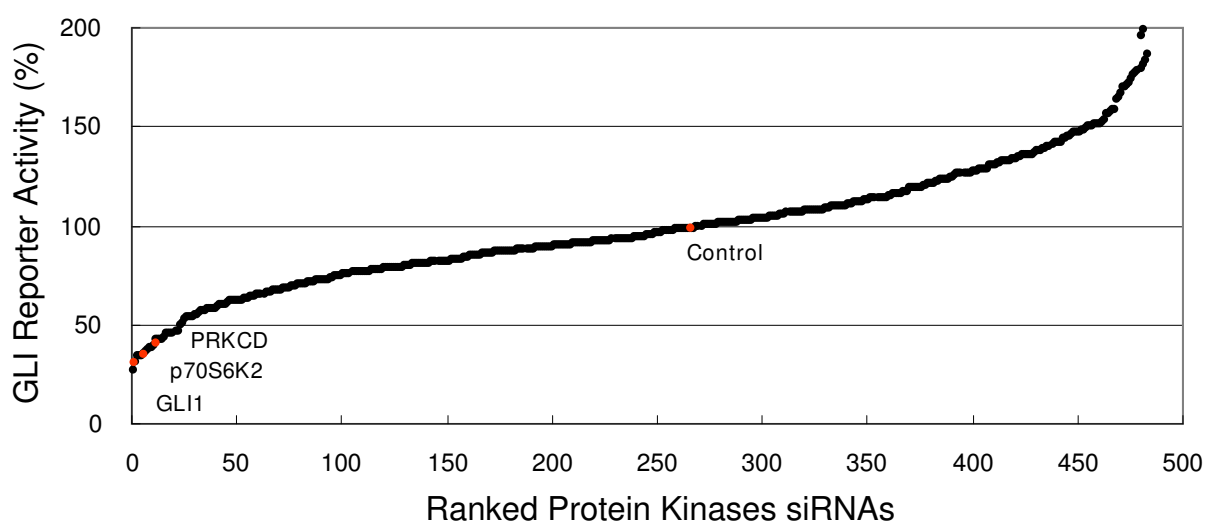

Figure I

Kinome-wide siRNA screen to find HH pathway regulatory kinases in NSCLC A549 cells. A, Identification of GLII cascade activated NSCLC cell lines. The mRNA expression level of GLII in the eight NSCLC cells was measured with quantitative RT-PCR. Data were normalized to internal $\beta$-actin expression and are presented as the mean and SD of three independent experiments. B, Establishment of stable A549 cell lines harboring GLI regulatory $\beta$-lactamase reporter gene activity. The A549GLI cells were treated with siRNAs as a control, GLII, GLI2, GLI3 or PLKI to confirm that $\beta$-lactamase was under the control of GLII transcription factor. PLKI-siRNA was used as a negative control to confirm that cytotoxicity did not affect reporter activity. Data are the mean and SD of three independent experiments. C, Results of the kinome-wide siRNA screen composed of about 500 protein kinases. The GLI reporter activity was shown as a percentage normalized to control-siRNA treated cells. **, $P \leq 0.0$ I, compared with control.

and H1915). Of these, A549 was chosen for the subsequent kinome-siRNA screen, as the status of cancerrelated pathways in A549 cells has been well characterized, and A549 cells are amenable to sufficient siRNA transfection. GLI-regulatory $\beta$-lactamase reporter gene was transferred to the A549 cells and stable cell lines constitutively expressing the reporter gene were established (A549-GLI). Examination of reporter activity after introduction of GLI1-siRNA into the A549-GLI cells to confirm that the GLI regulatory $\beta$-lactamase reporter gene was under the control of GLI1 transcription factor, showed that reporter gene activity was reduced to $32 \%$ compared with control-siRNA treated cells (Fig. 1B). The silencing of GLI3, known to be a transcriptional repressor of GLI-regulatory target genes, did not affect $\beta$-lactamase activity, indicating that the prominently over-expressed GLI1 in A549 is a major regulator of the $\beta$-lactamase reporter gene. This suggests that A549-GLI cells were well suited to the kinome-wide siRNA screen to identify kinases that influence HH/GLI1 pathway-mediated transcription. To find kinases that affect the GLI regulatory reporter gene, the A549-GLI cells were transfected by lipofection method with kinome-siRNAs comprising about 500 protein kinases. $\beta$-lactamase activity was measured $72 \mathrm{hr}$ after transfection to examine the inhibitory effect on the reporter gene by each kinase (Fig. 1C). In the large scale siRNA screen, GLI1-siRNA was also included as a positive control, and about $70 \%$ inhibition of reporter activity was constantly observed by the GLI1 disruption, demonstrating that accuracy/reproducibility of the assay were relia- 
ble. The result of the siRNA screen illustrated that 17 kinases out of 500 siRNAs reduced the GLI-mediated reporter gene activity to less than $45 \%$. As protein kinase $\mathrm{C}$ delta (PRKCD) was previously reported to positively regulate HH/GLI1 pathway [32], kinase siRNAs that down-regulated the reporter activity more than the cutoff value $(45 \%)$, which was determined based on the reduction level for PRKCD-siRNA, were selected as promising candidates as positive regulators for HH/GLI1 pathway. Among the kinase siRNAs that were hit, p70S6K2 (RPS6KB2) significantly reduced GLI-mediated reporter gene transcription activity to $38 \%$. Although it is well recognized that inhibition of p70S6K2 down-regulates the oncogenic PI3K pathway, the effect of p70K6K2 on the activity of the HH pathway has not been reported. There- fore, we focused on p70S6K2 in the subsequent confirmation and validation studies.

\section{Inhibition of p70S6K2 reduces GLII regulatory transcription}

The confirmation studies verified the down-regulation of GLI1 transcription by $p 70 S 6 K 2$ inhibition. Treatment of A549-GLI with a different sequence of p70S6K2-siRNA from the one used in the large scale siRNA screen, followed by recovery of RNA from the transfected cells 48-hr after siRNA transfection, and measurement of the silencing level of $p 70 S 6 K 2$ by quantitative reverse transcriptasepolymerase chain reaction (RT-PCR) (Fig. 2A) showed that $p 70 S 6 K 2$ mRNA expression was reduced to $11 \%$ compared with control-siRNA treated cells. This illustrates that sufficient level of repression was achieved for p70S6K2.
A
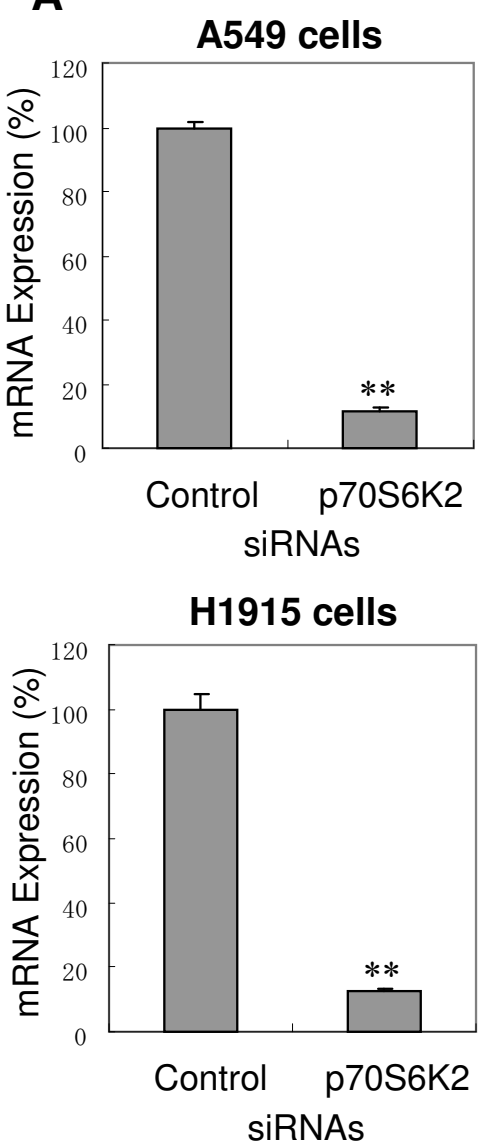

B
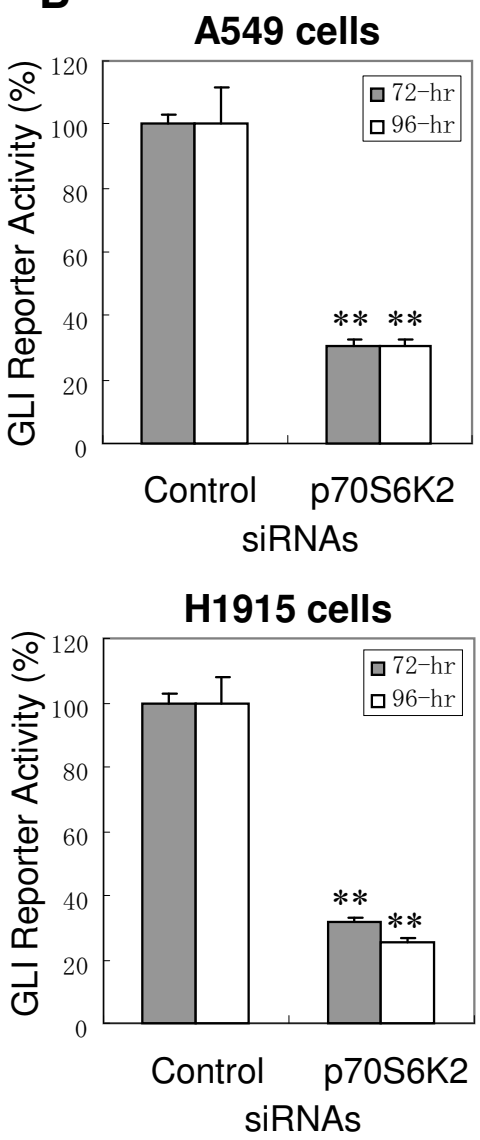

C
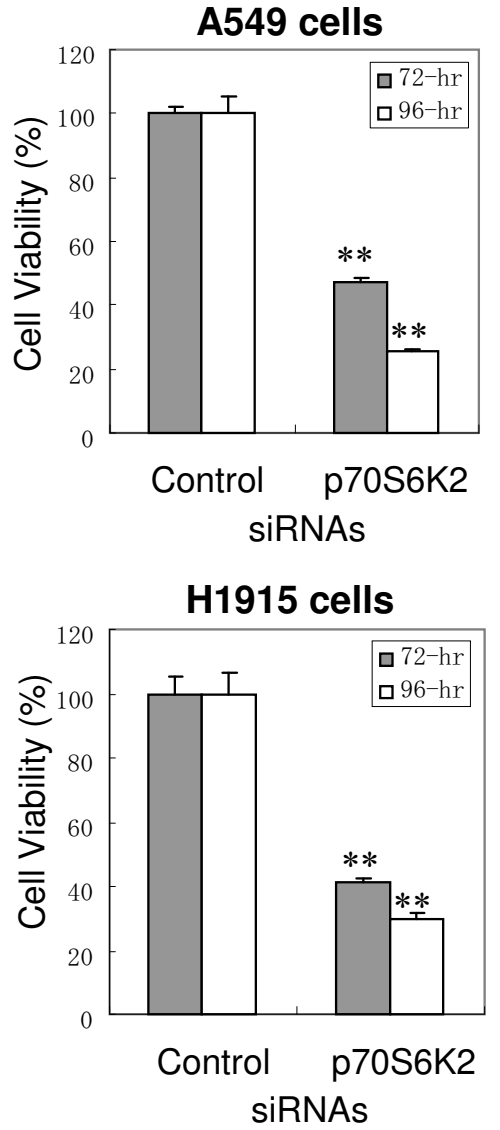

Figure 2

p70S6K2-silencing by siRNA down-regulates GLI regulatory reporter gene. A, mRNA-silencing level of $p 7056 K 2$ by siRNA. mRNA expression levels of $p 7056 K 2$ in the control- or $p 7056 K 2$-siRNA treated cells were measured $48 \mathrm{hr}$ after siRNA transfection by quantitative RT-PCR. B, Effect of p70S6K2-silencing on GLI reporter gene activity. GLI regulatory $\beta$-lactamase activity was measured 72 and $96 \mathrm{hr}$ after siRNA transfection. The value was normalized to cell number. C, Effect of p70S6K2silencing on cell viability. Cell viability was measured 72 and $96 \mathrm{hr}$ after siRNA transfection as described in the materials and methods. Data are the mean and SD of three independent experiments. $* *, P \leq 0.0 \mathrm{I}$, compared with control. 
Similar to the large scale siRNA screen, $69 \%$ reduction in GLI regulatory reporter gene activity was observed at 72 and $96 \mathrm{hr}$ after transfection (Fig. 2B), which was equivalent to the reduction level achieved by GLI1-siRNA. Measurement of cell viability after $p 70 S 6 K 2$ inhibition by quantifying ATP level as an index of metabolically vital cells allowed examination of whether proliferation of A549 cells was dependent on the GLI1 pathway. A reduction in cell viability of about $50 \%$ and $70 \%$ was observed 72 and $96 \mathrm{hr}$ respectively after transfection (Fig. 2C). Reduction in both GLI reporter gene activity and cell viability by $p 70 S 6 K 2$-silencing was also confirmed in $\mathrm{H} 1915$ cells that stably expressed GLI regulatory $\beta$-lactamase gene (Fig. 2A-2C bottom panels). In addition to the GLI regulatory $\beta$-lactamase reporter gene, expressions of endogenous GLI1 regulatory genes were quantified by RT-PCR. Cyclin D1, part of G1/S cell cycle machinery, is known to be mainly controlled by GLI1 and GLI2 in HH pathway activated cells [5]. The expression of $\gamma$-catenin, which is involved in apoptosis, is repressed by GLI1 transcription factor [6]. Both cyclin D1 and $\gamma$-catenin were significantly down- or up-regulated respectively by the increasing concentration of p70S6K2-siRNA (Fig. $3 \mathrm{~A}$ and $3 \mathrm{~B}$ ). The expression changes caused by the inhibition of $p 7056 K 2$ were similar to those caused by GLI1 inhibition: 50\% reduction of Cyclin D1 and 1.7-fold induction of $\gamma$-catenin.

\section{p70S6K2-silencing degrades GLII transcription via activating GSK3 $\beta$}

GSK3 $\beta$ phosphorylates GLI and negatively modulates its activity, leading to the destabilization of the transcription factor. p70S6Ks down-regulates the activity of GSK3 $\beta$ by phosphorylating Ser9 residue [33]. It was hypothesized that the mechanism underlying the p70S6K2 inhibitionmediated down-regulation of GLI1 transcription activity is through the activation of GSK3 $\beta$ which leads to GLI destabilization/inactivation. To examine this hypothesis, phosphorylation levels of GSK3 $\beta$ at Ser9 residue after p70S6K2-silencing by siRNA in A549 cells were measured. Through western blotting, it was observed that p70S6K2 levels were remarkably reduced (Fig. 4A), which was in accordance with mRNA expression levels shown previously. Although the phosphorylated form of GSK3 $\beta$ (Ser9) was not affected by control-siRNA treatment, the level of phospho-GSK3 $\beta$ was significantly reduced upon the treatment of p70S6K2-siRNA in a time-dependent manner (Fig. 4A). Total GSK3 $\beta$ was also unaltered by the siRNA transfection. As GLI1 is stabilized by the inactivated form of phosporylated-GSK3 $\beta$, GLI1 protein level was investigated by western blotting when $p 70 S 6 K 2$ was silenced. Upon the silencing of $p 70 S 6 K 2$ by siRNA, significant reduction of GLI1 protein level was observed compared with the control (Fig. 4B).
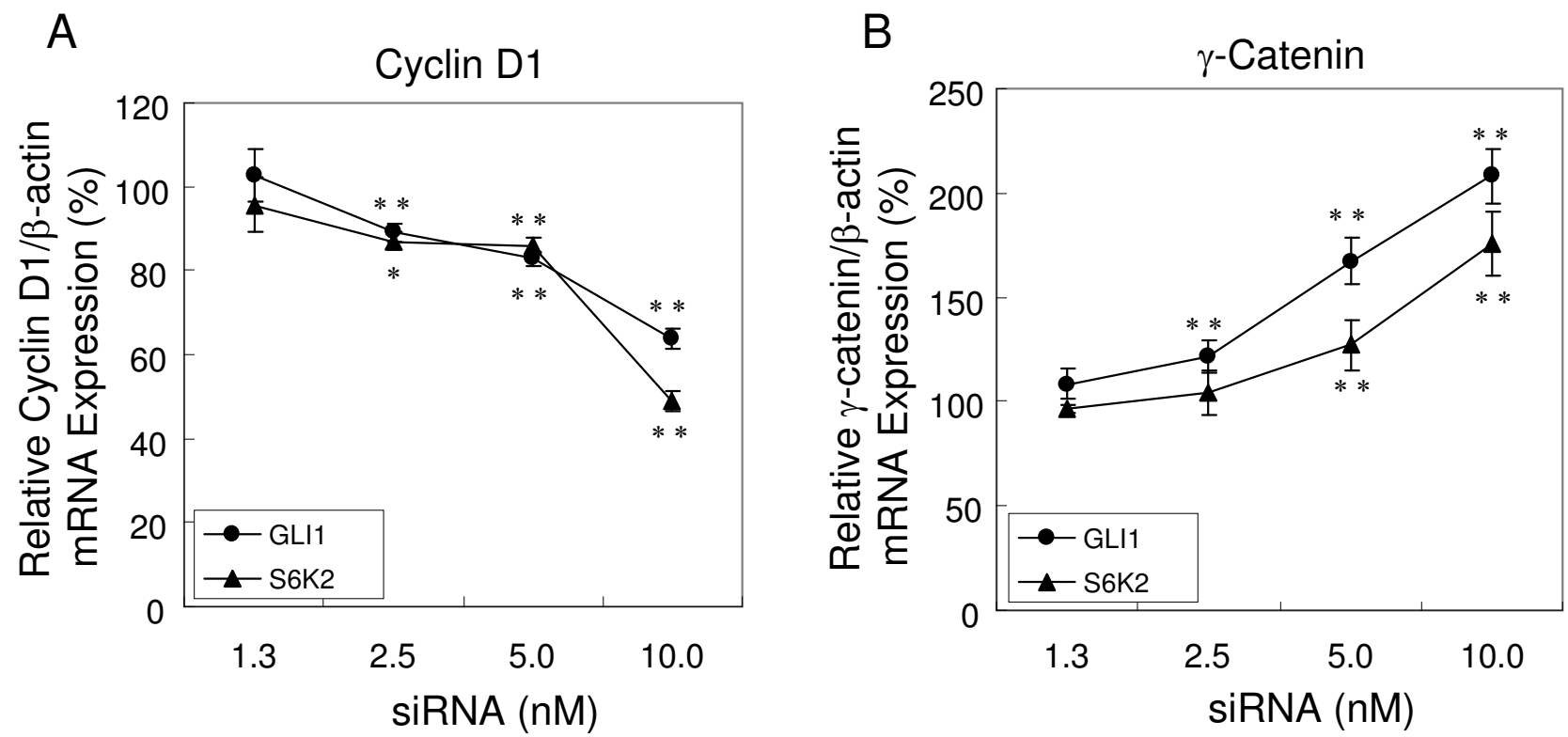

Figure 3

p7056K2-silencing by siRNA decreases or increases expression of endogenous GLII regulatory genes. A, Cyclin DI mRNA expression level. B, $\gamma$-catenin mRNA expression level. mRNA expression levels of GLII-regulatory genes were measured $48 \mathrm{hr}$ after siRNA transfection by quantitative RT-PCR in A549 cells treated with GLII-siRNA or p70S6K2-siRNA. Data were normalized to internal $\beta$-actin expression and are presented as the mean and SD of three independent experiments. $*, P \leq 0.05 ; * *, P \leq 0.0$ I compared with control. 
A

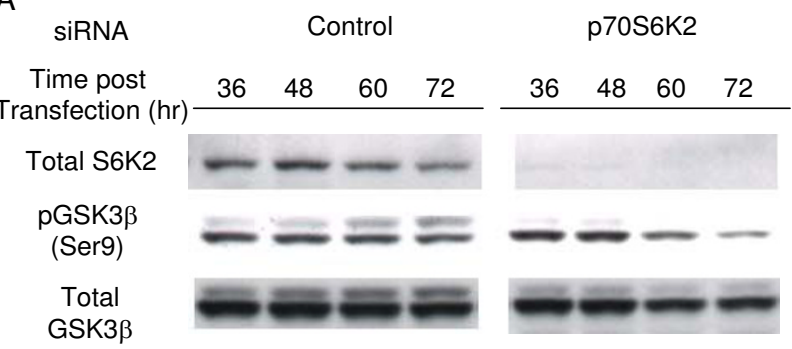

B

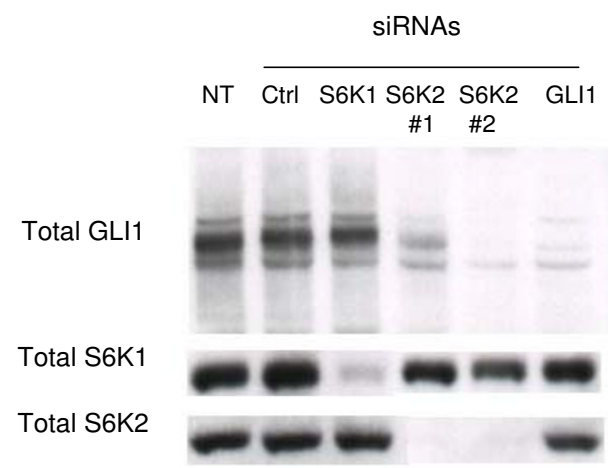

Figure 4

Inhibition of p70S6K2 causes GLII degradation through reduction in phospho-GSK3 $\beta$ at Ser9 residue. $A$, Phosphorylated-GSK3 $\beta$ level of cells treated with p70S6K2 siRNA. Cell lysates were recovered and subjected to western blotting analysis to detect total p70S6K2, total GSK $3 \beta$ and phospho-GSK3 $\beta$ respectively at the indicated time points after siRNA transfection. B, GLII protein level of cells treated with p70S6K2-siRNA. A549 cells were also treated with siRNAs (control, p70S6KI, p70S6K2, and GLII), and cell lysate was subjected to western blotting with GLII, p70S6K I and p70S6K2 antibodies $72 \mathrm{hr}$ after transfection.

P70S6K2 is well recognized as a downstream effector of the PI3K pathway $[27,29]$, and no relationship between p70S6K2 and the $\mathrm{HH}$ pathway has yet been reported. Therefore, to further support the novel finding that p70S6K2, as one of the components of the PI3K pathway, modulates GLI1 transactivation ability, we examined whether phosphatidylinositol 3-kinase catalytic alpha polypeptide (PIK3CA) inhibition reduces GLI regulatory reporter gene activity. In agreement with the p70S6K2 inhibition-mediated reduction in the reporter gene, PIK3CA silencing by siRNA also decreased GLI regulatory reporter gene activity to 44\% in A549-GLI cells (Fig. 5A). The effect of pharmacological inhibition of PI3K on the GLI reporter gene was also examined. While SMOH inhibition by cyclopamine did not affect GLI reporter gene activity in accordance with a previous study that showed GLI1 activation is ligand independent in A549 cells [18], a significant decrease in activity was observed by inhibition of PI3K with LY294002 (Fig. 5B).

The results demonstrated so far, which indicate that p70S6K2-inhibition down-regulated GLI1-mediated transcription via regulation of GSK3 $\beta$ function, were predominately investigated in A549 cells. The activation of GSK3 $\beta$ and GLI 1 degradation by p70S6K2-silencing was also confirmed in the H1915 cell line.

\section{Discussion}

A number of researchers have reported the development of HH/GLI1 cascade inhibitors as a new class of antitumor agent. For HH ligand-dependent cancers, pharmacological inhibition of the upstream components of the pathway offers an effective anti-tumor action. Indeed, ligand neutralizing antibodies or cyclopamine (an $\mathrm{SMOH}$ inhibitor) in preclinical studies have shown significant progress in regressing tumor development $[5,12]$. It has been reported, however, that GLI1 signaling is activated in a subset of NSCLC through the mechanism of overexpression of GLI1 transcription factor with no deregulation of $\mathrm{PTCH}$ or $\mathrm{SMOH}$ [18]. This signaling activation is ligandindependent, given the fact that cyclopamine had little effect on both cell growth and GLI target gene expression in NSCLC cells. In order to suppress the HH pathway, novel therapeutic targets to intervene in the GLI1 cascade in NSCLC need to be identified. As kinases are widely recognized as druggable proteins which are amenable to the development of small molecule chemical inhibitors, a kinome-wide siRNAs screen was performed to identify kinase regulators of the $\mathrm{HH}$ pathway. Unexpectedly, silencing of $p 70 S 6 K 2$, a key regulator of the PI3K pathway, remarkably reduced the activity of GLI regulatory gene, indicating that p70S6K2 may serve as a therapeutic target to inactivate the $\mathrm{HH}$ cascade in cancer. The results of this study demonstrate that p70S6K2- and GLI1-silencing achieved similar levels of suppression of the GLI regulatory reporter gene. This suggests that pharmacological inhibition of p70S6K2 would sufficiently down-regulate the HH/GLI1 cascade in a subpopulation of NSCLCs with GLI1 overexpression.

The cross-talk between the HH pathway and other cancer relevant pathways has been extensively studied. Stimulation of PRKCD activates ERK signaling and up-regulates GLI transcription without the addition of an $\mathrm{HH}$-ligand [32], indicating the contribution of the PRKCD/ERK pathway to GLI activation. Both activation and inhibition of PRKCD by phorbol esters and pharmacological intervention respectively has illustrated that PRKCD controls GLI activation of $\mathrm{HH}$ signaling. The present data from the kinome-wide siRNA screen also identified PRKCD-siRNA as a negative regulator of the $\mathrm{HH}$ pathway (Table 1); supporting previous evidence that PRKCD functions to con- 
A

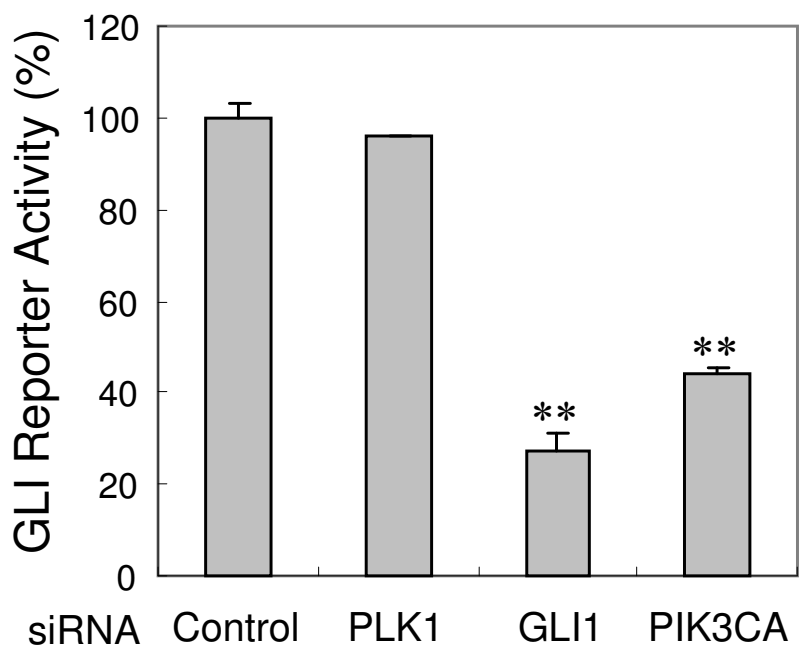

$\mathrm{B}$

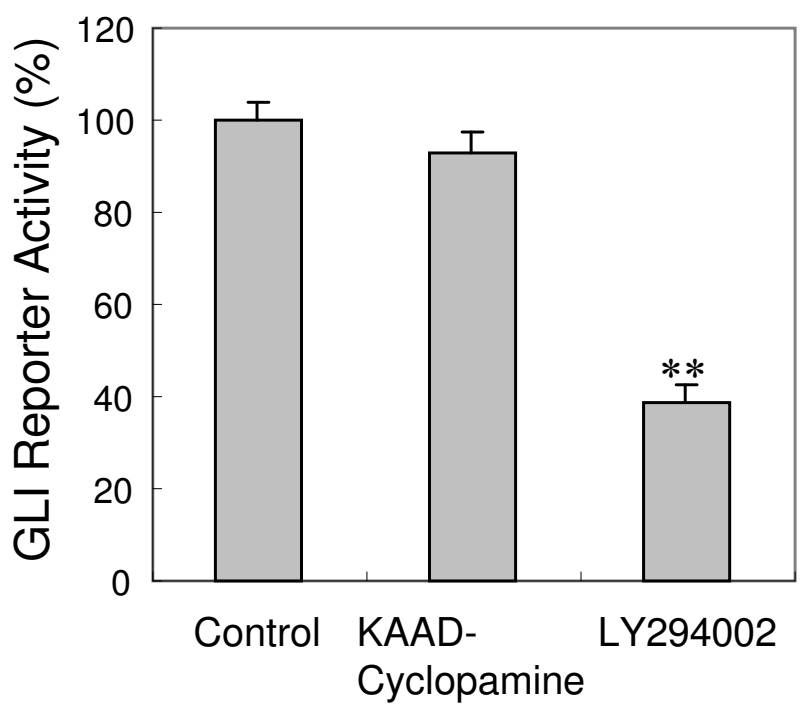

\section{Figure 5}

GLI reporter gene activity reduction by PIK3CA-inhibition. A, Effect of PI3K-silencing by siRNA on GLI regulatory reporter gene. GLI regulatory reporter gene activity was measured by $\beta$-lactamase assay $72 \mathrm{hr}$ after siRNA transfection (PLKI, GLII and PIK3CA) into A549-GLI cells. PLKI-siRNA was treated as a negative control to confirm that cytotoxicity did not affect reporter activity. GLII-siRNA was used as a positive control. B, Effect of PI3K-inhibition by LY294002 on GLI regulatory reporter gene. The A549-GLI cells were treated with PI3K inhibitor, LY294002 (90 $\mu$ M) and SMOH inhibitor KAADcyclopamine $(800 \mathrm{nM})$ respectively. $\beta$-lactamase activity was measured $12 \mathrm{hr}$ after treatment. Data are the mean and SD of three independent experiments. $* *, P \leq 0.0$ I compared with control.

trol the GLI1cascade. Recent advances in stem cell biology have also presented cross-talk between the $\mathrm{HH}$ pathway and other developmental pathways such as Wnt, Hox and Notch signaling [34,35]. Examples include a study on chronic myeloid leukemia stem cells, which showed that HH-dependent Stat 3 activation orchestrates down-regulation of Hox genes such as HoxA2 and HoxB4. With respect to the association of $\mathrm{HH}$ and $\mathrm{PI} 3 \mathrm{~K}$ pathways, a pioneering study showed that PI3K itself and AKT were found to be essential for the activation of the GLI reporter gene in response to $\mathrm{HH}$ stimulus in non-tumorigenic NIH3T3 cells harboring the GLI regulatory reporter gene, the expression of which is regulated in an $\mathrm{HH}$ ligand dependent manner [36]. The same study also indicated that upregulation of the GLI reporter gene by PI3K/AKT activation is mediated by controlling PKA activity. Singh and colleagues also reported that PI3K/AKT contributes to activation of the HH/GLI1 signaling pathway in ALK-positive anaplastic large cell lymphoma (ALCL), but not in ALK-negative ALCL [37]. However, the involvement of p70S6 kinases was not investigated. The current study provides additional evidence that the PI3K pathway contributes to the activation of the GLI1 cascade in NSCLC cells. Moreover, the mechanism relating PI3K to GLI1 regula- tion observed in this study is novel and distinct from the previous study in that the downstream effector of PI3K pathway, p70S6K2, controls GLI-mediated transcription via phosphorylating GSK3 $\beta$ which regulates GLI1 stabilization (Fig. 6).

The kinome-wide siRNA screen of the HH signaling pathway performed in the present study found that p70S6K2silencing suppresses GLI1-regulatory genes, but $p 70 S 6 \mathrm{~K} 1$ silencing does not. Subsequent studies also revealed that the mechanism for down-regulation in the GLI1 cascade is caused by $p 70 S 6 K 2$-silencing. Recent studies have facilitated our understanding that p70S6K1 and p70S6K2 possess redundant and distinct functions in cell signaling transduction [38]. An example of a commonly conserved function is that both $\mathrm{p} 70 \mathrm{~S} 6 \mathrm{~K} 1 / 2$ kinases transduce the signal in the down stream of the PI3K/mTOR cascade to accelerate protein biosynthesis. In the present siRNA screen, however, p70S6K1 was not identified as a GLI1 cascade inhibitory siRNA. The result that $p 7056 K 1$-siRNA treatment did not affect the HH/GLI1 cascade in NSCLC cells was also carefully confirmed by independent experiments which measured reduction in p70S6K1 expression and GLI regulatory reporter gene activity (data not 


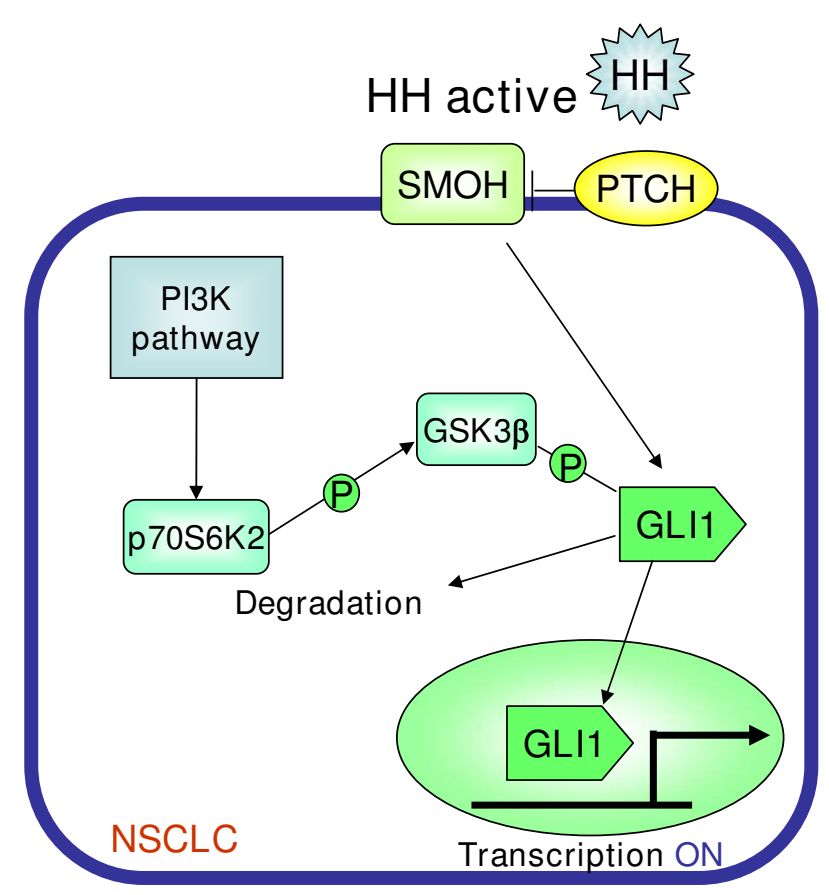

Figure 6

Proposed model of the relationship between p70S6K2 and the HH pathway. The activation of the canonical $\mathrm{HH}$ pathway is initiated by binding of the $\mathrm{HH}$ ligand to its receptor $\mathrm{PTCH}$, which relieves the repression of $\mathrm{SMOH}$. The activation of $\mathrm{SMOH}$ is translated into GLI zincfinger transcription factors. Glycogen synthase kinase-3 beta (GSK3 $\beta$ ) negatively regulates GLI transcription factors cooperating with other kinases such as PKA and CKIs. GSK3 $\beta$ is negatively regulated through phosphorylation by P70S6K 2 which is a downstream effecter of the PI3K pathway.

shown). Moreover, simultaneous double-knockdown of p70S6K1 and p70S6K2 was investigated to examine any synergistic effect on the inhibition of the GLI1 cascade. This resulted in no enhancing effect on the GLI reporter gene by $p 70 S 6 K 1$-siRNA. This indicates that the role of p70S6K2 in inhibiting the $\mathrm{HH}$ pathway may be distinct from that of p70S6K1, although we cannot eliminate the possibility that p70S6K1 may exert similar function in different types of cells. Further studies to examine expression/activation levels of p70S6K1/2 and the GLI1 cascade in diverse types of clinical samples and cell lines would provide some insights on this issue.

\section{Conclusion}

We report herein that p70S6K2 positively regulates GLI1mediated transcription through modulating GSK3 $\beta$ in NCSLC. Given the recent finding that various types of tumors have deregulations in the HH/GLI cascade independent of the $\mathrm{HH}$ ligand, in which modulation of upstream components are less effective [18], it is impera- tive that novel therapeutic targets for the GLI1 cascade be identified. The identification of p7056 2 as a positive regulator of GLI-mediated transcription provides an alternative strategy for developing therapeutic agents for ligandindependent HH/GLI-activated tumors.

\section{Methods \\ Reagents}

PI3K inhibitor, LY294002, and KAAD-cyclopamine were purchased from Merck KGaA (Dharmstadt, Germany). Cell culture reagents and media were obtained from Invitrogen (Carlsbad, CA).

\section{Establishment of stable cell lines of A549 harboring GLI regulatory reporter gene}

A549 cells were transfected with pLenti-bsd/GLI-bla vector (Invitrogen), which contains $\beta$-lactamase reporter gene under the transcriptional control of a $(8 \times)$ Gli response element with tata-minimal promoter, by lipofection using Lipofectamine reagent (Invitrogen). The cells transfected with the vector were cultured with growth medium containing $3.8 \mu \mathrm{g} / \mathrm{ml}$ of blasticidin for 14 days, and stable cell lines were established. Several stable clones were transfected with GLI1 siRNA and a few clones were identified in which $\beta$-lactamase activity was reduced by more than $70 \%$ with GLI1-silencing.

siRNA transfection and measurement of mRNA expression The sequence of $p 70 S 6 K 2$ siRNA used in the present experiments, other than kinome-wide siRNA screen, was GCCUAGAGCCUGUGGGACAtt (B-bridge, Mountain View, CA). The phenotypes observed in the p70S6K2 were confirmed by two additional sequences, GGUGUUCCAGGUGCGAAAGtt (Applied Biosystems/Ambion, Austin, TX) and GCAGAGAACCGGAAGAAAAtt (B-bridge). The following siRNAs were also used: GLI1-siRNA (M003896-00-0020: Thermo Fisher Scientific Inc., Waltham, MA); polo-like kinase 1 (PLK1)-siRNA (M-003290-010010: Thermo Fisher Scientific Inc.); control-siRNA (D001810-01-05: Thermo Fisher Scientific Inc.); and, human kinome siRNA set (AM80010V3, Applied Biosystems/Ambion). For siRNA transfection, 900 cells were seeded per well in 96-well plate and incubated for $24 \mathrm{hr}$. siRNA was mixed with a lipofection reagent, siLentFect (Bio-Rad, Hercules, CA) according to the manufacturer's instructions, and transfected into the A549 cells. mRNA was recovered and extracted $48 \mathrm{hr}$ after transfection with RNAeasy (Qiagen, Hilden, Germany). Reverse transcription was performed for $500 \mathrm{ng}$ of total RNA, and the cDNA obtained was applied to TaqMan PCR for quantification of mRNA expression. The primers and probe used for the quantitative polymerase chain reaction (qPCR) were: p70S6K2 (Hs00177689-M1, Applied Biosystems, Foster City, CA); GLI1 (Hs00171790-M1, Applied Biosystems), Cyclin D1 (Hokkaido system science, Sapporo, 
Table I: Kinase siRNAs suppressing GLI-mediated transcriptional activity

\begin{tabular}{llc}
\hline Kinases & Official Full Name & GLI Reporter Activity (\%) \\
\hline ADCK5 & aarF domain containing kinase 5 & $27 \pm 0.7$ \\
TNIK & TRAF2 and NCK interacting kinase & $31 \pm 2.9$ \\
PIM3 & pim-3 oncogene & $34 \pm 2.8$ \\
PAK6 & P2I protein (Cdc42/Rac)-activated kinase 6 & $35 \pm 8.6$ \\
DCLK2 & doublecortin-like kinase 2 & $35 \pm 1.7$ \\
ANKKI & ankyrin repeat and kinase domain containing I & $35 \pm 1.4$ \\
PCTK3 & PCTAIRE protein kinase 3 & $36 \pm 4.8$ \\
PRKD2 & protein kinase D2 & $37 \pm 5.3$ \\
P7OS6K2 & ribosomal protein S6 kinase, polypeptide 2 & $38 \pm 3.6$ \\
NLK & nemo-like kinasae & $39 \pm 1.4$ \\
DKFZP434C13I & unc-5I-like kinase 3 & $40 \pm 3.6$ \\
MASTL & microtubule associated serine/threonine kinase-like & $42 \pm 2.0$ \\
LATS2 & large tumor suppressor, homolog 2 & $42 \pm 0.5$ \\
KSR2 & kinase suppressor of ras 2 & $43 \pm 0.5$ \\
STK38L & serine/threonine kinase 38 like & $43 \pm 2.8$ \\
MLK4 & mixed lineage kinase 4 & $44 \pm 1.6$ \\
PRKCD & protein kinase C, delta & $45 \pm 1.1$ \\
\hline
\end{tabular}

Japan); and, $\gamma$-catenin (Hs00158408-M1, Applied Biosystems). Data were collected and analyzed using an ABI 7900HT Fast Real-Time PCR System (Applied Biosystems). The relative mRNA expression data were normalized to $\beta$-actin expression, measured with pre-designed qPCR primers and probe $(4310881 \mathrm{E}$, Applied Biosystems).

\section{Cell viability assay and $\beta$-lactamase assay}

Cell viability was measured by CellTiter-Glo Luminescent Cell Viability Assay (Promega, Madison, WI), 72 or 96 hr after siRNA transfection. An equal volume $(100 \mu \mathrm{L})$ of CellTiter-Glo Reagent was added to medium, and mixed gently for $2 \mathrm{~min}$ on an orbital shaker. The solution was incubated at room temperature for $10 \mathrm{~min}$ to allow it to stabilize and luminescence to appear, after which the luminescence was measured. The activity of $\beta$-lactamase was quantified with GeneBLAzer ${ }^{\mathrm{TM}}$ Detection Kits (Invitrogen) according to the manufacturer's instructions. A $6 \times$ substrate loading solution was added to the cells to $1 \times$ final concentration and the cells in the buffer were incubated for $6 \mathrm{hr}$. $\beta$-lactamase activity was then measured using a fluorescent plate reader. The $\beta$-lactamase activity was normalized to cell number, measured by CellTiterGlo Luminescent Cell Viability Assay (Promega).

\section{Immunoblotting}

For immunoblotting of total and phosphorylated GSK3 $\beta$ and GLI1, cell lysate was extracted from A549 or H1915 cells with a lysis buffer (50 mM HEPES, $250 \mathrm{mM} \mathrm{NaCl}$, $0.1 \%$ NP-40, $0.1 \mathrm{mM}$ DTT) comprising a 1:00 dilution of protease inhibitor cocktail (Thermo Fisher Scientific Inc. Rockford, IL) containing AEBSF, Aprotinin, Bestatin, E-64, Leupeptin, Pepstatin A), and a 1:00 dilution of phosphatase inhibitor cocktail (Thermo Fisher Scientific Inc.) containing sodium fluoride, sodium orthovanadate, sodium pyrophosphate and $\beta$-glycerophosphate. The extracted $20 \mu \mathrm{g}$ of total protein was subjected to $10 \%$ SDSPAGE analysis. Proteins were visualized by ECL chemiluminescence reagents (GE Healthcare UK Ltd., Buckinghamshire, UK) using primary antibodies specific to total GSK3 $\beta$ (\#9315, Cell Signaling Technology, Danvers, MA), phosphorylated GSK3 $\beta$ at Ser9 residue (\#9336, Cell Signaling Technology) and GLI1 (\#2553, Cell Signaling Technology), p70S6K1 (\#9202, Cell Signaling Technology) and p70S6K2 (sc-9379, Santa Cruz Biotechnology, Santa Cruz,

CA).

\section{Competing interests}

The authors declare that they have no competing interests.

\section{Authors' contributions}

SM was involved in the design and execution of the experiments and drafted the manuscript. AK conducted most of the experiments and contributed to manuscript preparation. HH contributed to the overall experimental design. All authors read and approved the final manuscript.

\section{References}

I. Varjosalo M, Taipale J: Hedgehog: functions and mechanisms. Genes Dev 2008, 22:2454-72.

2. Epstein EH: Basal cell carcinomas: attack of the hedgehog. Nat Rev Cancer 2008, 8:743-54.

3. Ruiz i Altaba A, Mas C, Stecca B: The GLI code: an information nexus regulating cell fate, stemness and cancer. Trends Cell Biol 2007, 17:438-47.

4. Kasper M, Regl G, Frischauf AM, Aberger F: GLI transcription factors: mediators of oncogenic Hedgehog signalling. Eur J Cancer 2006, 42:437-45.

5. Hegde GV, Munger CM, Emanuel K, Joshi AD, Greiner TC, Weisenburger DD, Vose JM, Joshi SS: Targeting of sonic hedgehog-GLI signaling: a potential strategy to improve therapy for mantle cell lymphoma. Mol Cancer Ther 2008, 7:1450-60.

6. Yoon JW, Kita Y, Frank DJ, Majewski RR, Konicek BA, Nobrega MA, Jacob $\mathrm{H}$, Walterhouse $D$, lannaccone $\mathrm{P}$ : Gene expression profiling 
leads to identification of GLII-binding elements in target genes and a role for multiple downstream pathways in GLIIinduced cell transformation. J Biol Chem 2002, 277:5548-55.

7. Rahnama F, Shimokawa T, Lauth M, Finta C, Kogerman P, Teglund S, Toftgård R, Zaphiropoulos PG: Inhibition of GLII gene activation by Patched I. Biochem J 2006, 394: 19-26.

8. Price MA, Kalderon D: Proteolysis of the Hedgehog signaling effector Cubitus interruptus requires phosphorylation by Glycogen Synthase Kinase 3 and Casein Kinase I. Cell 2002, 108:823-35.

9. Jia J, Amanai K, Wang G, Tang J, Wang B, Jiang J: Shaggy/GSK3 antagonizes Hedgehog signalling by regulating Cubitus interruptus. Nature 2002, 416:548-52.

10. Jia J, Zhang L, Zhang Q, Tong C, Wang B, Hou F, Amanai K, Jiang J: Phosphorylation by double-time/CKlepsilon and CKIalpha targets cubitus interruptus for Slimb/beta-TRCP-mediated proteolytic processing. Dev Cell 2005, 9:819-30.

II. Visvader JE, Lindeman G]: Cancer stem cells in solid tumours: accumulating evidence and unresolved questions. Nat Rev Cancer 2008, 8:755-68.

12. Kiselyov AS: Targeting the hedgehog signaling pathway with small molecules. Anticancer Agents Med Chem 2006, 6:445-9.

13. Hahn H, Wicking C, Zaphiropoulous PG, Gailani MR, Shanley S, Chidambaram A, Vorechovsky I, Holmberg E, Unden AB, Gillies S, Negus K, Smyth I, Pressman C, Leffell DJ, Gerrard B, Goldstein AM, Dean M, Toftgard R, Chenevix-Trench G, Wainwright B, Bale AE: Mutations of the human homolog of Drosophila patched in the nevoid basal cell carcinoma syndrome. Cell 1996, 85:84I-5I.

14. Johnson RL, Rothman AL, Xie J, Goodrich LV, Bare JW, Bonifas JM, Quinn AG, Myers RM, Cox DR, Epstein EH Jr, Scott MP: Human homolog of patched, a candidate gene for the basal cell nevus syndrome. Science 1996, 272:1668-7I.

15. Xie J, Murone M, Luoh SM, Ryan A, Gu Q, Zhang C, Bonifas JM, Lam CW, Hynes M, Goddard A, Rosenthal A, Epstein EH Jr, de Sauvage FJ: Activating Smoothened mutations in sporadic basal-cell carcinoma. Nature 1998, 39 I:90-2.

16. Raffel C, Jenkins RB, Frederick L, Hebrink D, Alderete B, Fults DW, James CD: Sporadic medulloblastomas contain PTCH mutations. Cancer Res 1997, 57:842-5.

17. Tostar U, Malm CJ, Meis-Kindblom JM, Kindblom LG, Toftgård R, Undén $A B$ : Deregulation of the hedgehog signalling pathway: a possible role for the PTCH and SUFU genes in human rhabdomyoma and rhabdomyosarcoma development. J Pathol 2006, 208: 17-25.

18. Yuan Z, Goetz JA, Singh S, Ogden SK, Petty WJ, Black CC, Memoli VA, Dmitrovsky E, Robbins DJ: Frequent requirement of hedgehog signaling in non-small cell lung carcinoma. Oncogene 2007, 26:1046-55.

19. Sanchez P, Hernández AM, Stecca B, Kahler AJ, DeGueme AM, Barrett A, Beyna M, Datta MW, Datta S, Ruiz i Altaba A: Inhibition of prostate cancer proliferation by interference with SONIC HEDGEHOG-GLII signaling. Proc Natl Acad Sci USA 2004, |01:|256|-6.

20. Kubo M, Nakamura M, Tasaki A, Yamanaka N, Nakashima H, Nomura $M$, Kuroki S, Katano M: Hedgehog signaling pathway is a new therapeutic target for patients with breast cancer. Cancer Res 2004, 64:607I-4.

21. Thayer SP, di Magliano MP, Heiser PW, Nielsen CM, Roberts DJ, Lauwers GY, Qi YP, Gysin S, Fernández-del Castillo C, Yajnik V, Antoniu $B$, McMahon M, Warshaw AL, Hebrok M: Hedgehog is an early and late mediator of pancreatic cancer tumorigenesis. Nature 2003, 425:85I-6.

22. Watkins DN, Berman DM, Burkholder SG, Wang B, Beachy PA, Baylin SB: Hedgehog signalling within airway epithelial progenitors and in small-cell lung cancer. Nature 2003, 422:313-7.

23. Rubin LL, de Sauvage F): Targeting the Hedgehog pathway in cancer. Nat Rev Drug Discov 2006, 5: 1026-33.

24. Gout I, Minami T, Hara K, Tsujishita Y, Filonenko V, Waterfield MD, Yonezawa K: Molecular cloning and characterization of a novel p70 66 kinase, p70 S6 kinase beta containing a prolinerich region. | Biol Chem 1998, 273:3006 I-4.

25. Park IH, Bachmann R, Shirazi H, Chen J: Regulation of ribosomal S6 kinase 2 by mammalian target of rapamycin. J Biol Chem 2002, 277:31423-9.
26. Filonenko VV, Tytarenko R, Azatjan SK, Savinska LO, Gaydar YA, Gout IT, Usenko VS, Lyzogubov VV: Immunohistochemical analysis of S6KI and S6K2 localization in human breast tumors. Exp Oncol 2004, 26:294-9.

27. Inoki K, Corradetti MN, Guan KL: Dysregulation of the TSCmTOR pathway in human disease. Nat Genet 2005, 37:19-24.

28. Pardo OE, Wellbrock C, Khanzada UK, Aubert M, Arozarena I, Davidson S, Bowen F, Parker PJ, Filonenko VV, Gout IT, Sebire N, Marais R, Downward J, Seckl MJ: FGF-2 protects small cell lung cancer cells from apoptosis through a complex involving PKCepsilon, B-Raf and S6K2. EMBO J 2006, 25:3078-88.

29. Martin KA, Schalm SS, Richardson C, Romanelli A, Keon KL, Blenis ]: Regulation of ribosomal S6 kinase 2 by effectors of the phosphoinositide 3-kinase pathway. J Biol Chem 200I, 276:7884-9I.

30. Lee-Fruman KK, Kuo C], Lippincott J, Terada N, Blenis ]: Characterization of S6K2, a novel kinase homologous to S6KI. Oncogene 1999, 18:5108-14.

3I. Oda K, Okada J, Timmerman L, Rodriguez-Viciana P, Stokoe D, Shoji K, Taketani Y, Kuramoto H, Knight ZA, Shokat KM, McCormick F: PIK3CA cooperates with other phosphatidylinositol 3'kinase pathway mutations to effect oncogenic transformation. Cancer Res 2008, 68:8I27-36.

32. Riobo NA, Haines GM, Emerson CP Jr: Protein kinase C-delta and mitogen-activated protein/extracellular signal-regulated kinase-I control GLI activation in hedgehog signaling. Cancer Res 2006, 66:839-45.

33. Meijer L, Flajolet M, Greengard P: Pharmacological inhibitors of glycogen synthase kinase 3. Trends Pharmacol Sci 2004, 25:47I-80.

34. Sengupta A, Banerjee D, Chandra S, Banerji SK, Ghosh R, Roy R, Banerjee $S$ : Deregulation and cross talk among Sonic hedgehog, Wnt, Hox and Notch signaling in chronic myeloid leukemia progression. Leukemia 2007, $21: 949-55$.

35. Yanai K, Nakamura M, Akiyoshi T, Nagai S, Wada J, Koga K, Noshiro $H$, Nagai E, Tsuneyoshi M, Tanaka M, Katano M: Crosstalk of hedgehog and Wnt pathways in gastric cancer. Cancer Lett 2008, 263: I 45-56.

36. Riobó NA, Lu K, Ai X, Haines GM, Emerson CP Jr: Phosphoinositide 3-kinase and Akt are essential for Sonic Hedgehog signaling. Proc Natl Acad Sci USA 2006, 103:4505-I0.

37. Singh RR, Cho-Vega JH, Davuluri Y, Ma S, Kasbidi F, Milito C, Lennon PA, Drakos E, Medeiros LJ, Luthra R, Vega F: Sonic hedgehog signaling pathway is activated in ALK-positive anaplastic large cell lymphoma. Cancer Res 2009, 69:2550-8.

38. Phin S, Kupferwasser D, Lam J, Lee-Fruman KK: Mutational analysis of ribosomal $\mathbf{S 6}$ kinase 2 shows differential regulation of its kinase activity from that of ribosomal S6 kinase I. Biochem J 2003, 373:583-91.

Publish with Bio Med Central and every scientist can read your work free of charge

"BioMed Central will be the most significant development for disseminating the results of biomedical research in our lifetime. "

Sir Paul Nurse, Cancer Research UK

Your research papers will be:

- available free of charge to the entire biomedical community

- peer reviewed and published immediately upon acceptance

- cited in PubMed and archived on PubMed Central

- yours - you keep the copyright
BioMedcentral 